\title{
Seaweed intake and blood pressure levels in healthy pre-school Japanese children
}

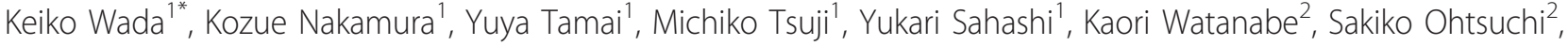
Keiko Yamamoto ${ }^{2}$, Kyoko Ando $^{2}$ and Chisato Nagata ${ }^{1}$

\begin{abstract}
Background: Few studies have examined whether dietary factors might affect blood pressure in children. We purposed to investigate whether seaweed intake is associated with blood pressure level among Japanese preschool children.

Methods: The design of the study was cross-sectional and it was conducted in autumn 2006. Subjects were healthy preschoolers aged 3-6 years in Aichi, Japan. Blood pressure and pulse were measured once by an automated sphygmomanometer, which uses oscillometric methods. Dietary data, including seaweed intake, were assessed using 3-day dietary records covering 2 consecutive weekdays and 1 weekend day. Of a total of 533 children, 459 (86.1 percent) agreed to be enrolled in our study. Finally, blood pressure measurement, complete dietary records and parent-reported height and weight were obtained for 223 boys and 194 girls.

Results: When we examined Spearman's correlation coefficients, seaweed intake was significantly negatively related to systolic blood pressure in girls $(P=0.008)$. In the one-way analysis of covariance for blood pressure and pulse after adjustments for age and BMI, the boys with the lowest, middle and highest tertiles of seaweed intake had diastolic blood pressure readings of $62.8,59.3$ and $59.6 \mathrm{mmHg}$, respectively $(P=0.11$, trend $P=0.038)$. Girls with higher seaweed intake had significantly lower systolic blood pressure readings $(102.4,99.2$ and $96.9 \mathrm{mmHg}$ for girls with the lowest, middle and highest tertiles of seaweed intake, respectively; $P=0.037$, trend $P=0.030$ ).

Conclusion: Our study showed that seaweed intake was negatively related to diastolic blood pressure in boys and to systolic blood pressure in girls. This suggests that seaweed might have beneficial effects on blood pressure among children.
\end{abstract}

Keywords: blood pressure, child, preschool, diet records, seaweed, nutrition

\section{Background}

Hypertension, which often coexists with diabetes, dyslipidemia and obesity, promotes atherosclerosis and contributes to the development of cardiovascular disease [1]. Hypertension is generally unusual among children, but many studies have shown the tracking of blood pressure from childhood to adulthood [2], and some studies have indicated that the process of atherosclerosis starts in childhood [3,4]. Thus, early intervention for high blood pressure is important in order to prevent cardiovascular disease later in life.

\footnotetext{
* Correspondence: dr_keiko@gifu-u.ac.jp

${ }^{1}$ Department of Epidemiology and Preventive Medicine, Gifu University

Graduate School of Medicine, 1-1 Yanagido, Gifu 501-1194, Japan

Full list of author information is available at the end of the article
}

Although there is much evidence for dietary risk factors for hypertension in adults [5-13], few studies of children have been reported [14-21]. Restricted salt intake and reduced alcohol consumption are recommended for adults [6]. The Dietary Approaches to Stop Hypertension (DASH diet), which is rich in fruits, vegetables and low-fat dairy products, has beneficial effects on blood pressure among adults [5-8]. The diet is rich in potassium and calcium, which have been reported to reduce blood pressure among adults $[8,9,13]$. A negative association between magnesium and blood pressure has also been reported among adults in some papers $[10,11,13]$. However, the role of diet in blood pressure among children is not well understood.

\section{Biomed Central}

(c) 2011 Wada et al; licensee BioMed Central Ltd. This is an Open Access article distributed under the terms of the Creative Commons Attribution License (http://creativecommons.org/licenses/by/2.0), which permits unrestricted use, distribution, and reproduction in any medium, provided the original work is properly cited. 
Seaweeds are traditional Japanese foods, and are consumed as they are (nori, kombu, hijiki) or as ingredients of rice balls (nori) and salads or soups (wakame). Seaweeds contain large quantities of dietary fiber, minerals, vitamins and polysaccharides [22]. Several experimental studies in animals [23-27] have shown that feeding on seaweed or its extract lowers blood pressure, suggesting that seaweed intake might affect blood pressure in humans. However, only a few epidemiological studies have reported an association between seaweed intake and blood pressure, and the results have been inconsistent [28-31]. These studies were conducted among adults, and the relationship of seaweed intake to blood pressure has not been investigated among children.

In this study, we purposed to investigate whether dietary seaweed intake is associated with blood pressure level among Japanese preschool children. We hypothesized that seaweed might beneficially affect blood pressure among children.

\section{Methods}

\section{Subjects and Design}

Subjects were children aged three to six years who attended one of two preschools in Aichi Prefecture, Japan. The details of the cohorts have been described elsewhere previously [32]. During October and November 2006, they underwent blood pressure measurement. Urine, which was first voided after a child waked up, was collected. Children's height, weight, health status, and lifestyles were inquired through a parent-administered questionnaire. Lifestyles included the time when they got up or went to bed, and a nap time. Physical activity was based on an outdoor playtime checklist by Burdette et al. [33]. The parents were also asked to record the children's dietary intake for covering 2 consecutive weekdays and 1 weekend day. Of a total of 533 preschool children, 459 (86.1 percent) agreed to be enrolled in our study, with their parents providing written informed consent. Finally, blood pressure measurement, complete dietary records and parent-reported height and weight were obtained for 417 of the children. This study protocol and the informed consent procedure were approved by the ethical board of Gifu University Graduate School of Medicine, Gifu, Japan.

\section{Dietary data}

To collect nutritional data, diet including seaweed intake was assessed using 3-day dietary records covering 2 consecutive weekdays and 1 weekend day. The parents received written instructions on recording the food intakes of the children. According to the instructions, they recorded the amount and kind of foods, beverages and dishes which were consumed by their children during each of three days. When they were in trouble with recording, our stuffs assisted them on the phone. Because our subjects usually ate a school-provided lunch, we obtained the menus from each kindergarten and our staffs, which were dieticians, checked the quantity left over after each meal. Individual nutrient intake was estimated using the Japanese Standard Table of Food Composition, $5^{\text {th }}$ revised and enlarged edition [22]. We calculated energy intake in kilocalories per day and seaweed and salt intake in grams per day. Seaweed intake was converted to dry volume units.

\section{Blood pressure and other measurements}

Systolic (SBP), diastolic blood pressure (DBP) and pulse were measured once by an automated sphygmomanometer (ES-H55, Terumo Co., Japan), which uses oscillometric methods. Measurements of blood pressure were conducted in midmorning. Children were not requested to be fasting. We used the appropriate size of blood pressure cuff based on each child's arm circumference. As a rule, measurements were taken from the upper arm. The subjects were measured in a sitting position after a few minutes of rest. The height and weight of children were based on parents' reports. Body mass index (BMI) was calculated as (weight in $\mathrm{kg}$ )/ (height in $\mathrm{m})^{2}$. From our subjects, we additionally obtained the measurements of the heights and weights of 103 of the children. Among them, intra-class correlation coefficients between measured and parent-reported data were $0.90,0.96$, and 0.78 in height, weight, and $\mathrm{BMI}$, respectively.

\section{Statistical analysis}

All analyses were performed separately for each sex. According to the nutrient density method, we divided seaweed and salt intake by total energy intake, and presented them as grams per 1,000 kcal of total energy. The dietary intakes such as total energy, seaweed and salt were skewed and hence were logarithmic transformed in all analyses.

The characteristics by sex were calculated as mean (standard deviation: SD). The geometric mean and 95\% confidence interval were computed on the log-transformed values and converted back to the original scale of measurement. We used Spearman's correlation coefficients to detect the association of blood pressure and pulse with age, height, weight, BMI, and intakes of total energy, salt or seaweed.

We divided the subjects into three groups according to tertile category (low, middle or high) of seaweed intake. Tertiles were derived based on the distribution of seaweed consumption in the current population. In order to elucidate the relationships of seaweed intake with SBP, DBP and pulse, we used a one-way analysis of covariance (ANCOVA) after adjustments for age and 
BMI. Tests for linear trend were performed on multiple regression analyses using continues variables in seaweed intake.

All analyses were conducted using the SAS computer program, version 9.1 (SAS Institute). All $\mathrm{P}$ values were calculated by a two-sided test. A P value of less than 0.05 was considered statistically significant in all analyses.

\section{Results}

The characteristics of studied subjects are shown in Table 1. Subjects were 223 boys and 194 girls. The averages (SD) of SBP and DBP were, respectively, 98.7 (13.0) and 60.6 (11.1) mmHg among boys. Those were 99.5 (12.4) $\mathrm{mmHg}$ for SBP and $62.2(11.8) \mathrm{mmHg}$ for DBP among girls. The average pulse rate of girls was higher than that of boys $(93.6 / \mathrm{min}$ in boys and $96.5 / \mathrm{min}$ in girls: $P=0.047)$. Total energy intake was greater in boys than in girls $(1446 \mathrm{kcal} /$ day in boys and $1337 \mathrm{kcal} /$ day in girls: $P<0.001)$. The geometric means of seaweed intake were 0.67 and $0.76 \mathrm{~g} /$ day in boys and girls, respectively $(P=0.096)$.

Age, height and weight were significantly negatively correlated with pulse in boys and girls (Table 2). BMI was positively associated with SBP in boys and girls. Total energy intake was neither associated with SBP, DBP nor pulse. Salt intake was also neither associated with SBP, DBP nor pulse. Seaweed intake was weakly, but significantly negatively related to SBP in girls (Spearman's $\mathrm{r}=-0.190, \mathrm{P}=0.008$ ). There were borderline-significant negative associations between seaweed intake and DBP in boys (Spearman's $\mathrm{r}=-0.112, \mathrm{P}=$ 0.096 ) and girls (Spearman's $r=-0.123, P=0.089$ ). In girls, the negative association between seaweed intake
Table 2 Spearman's correlation coefficients of blood pressure and pulse, with age, height, weight, BMI and diet

\begin{tabular}{lcccccc}
\hline & \multicolumn{3}{c}{ Boys $(\mathbf{n}=\mathbf{2 2 3})$} & \multicolumn{3}{c}{ Girls $(\mathbf{n}=\mathbf{1 9 4})$} \\
\cline { 2 - 7 } & SBP & DBP & pulse & SBP & DBP & pulse \\
\hline Age & $-0.125^{*}$ & -0.016 & $-0.318^{* * *}$ & -0.062 & -0.045 & $-0.212^{* * *}$ \\
Height & -0.046 & -0.021 & $-0.275^{* * *}$ & 0.036 & 0.011 & $-0.247^{* * *}$ \\
Weight & 0.081 & 0.021 & $-0.261^{* * *}$ & $0.142^{* *}$ & 0.089 & $-0.163^{* *}$ \\
BMl & $0.155^{* *}$ & 0.033 & -0.012 & $0.187^{* * *}$ & $0.124^{*}$ & $0.120^{*}$ \\
Total energy & 0.090 & 0.001 & -0.020 & 0.066 & -0.041 & -0.045 \\
intake & & & & & & \\
Salt intake & 0.018 & 0.005 & -0.070 & -0.097 & -0.013 & -0.058 \\
Seaweed & -0.071 & $-0.112^{*}$ & -0.031 & $-0.190^{* * *}$ & $-0.123^{*}$ & $-0.137^{*}$ \\
intake $^{\mathrm{a}}$ & & & & & &
\end{tabular}

SBP, systolic blood pressure; DBP, diastolic blood pressure

${ }^{a}$ Each intake was controlled for total energy intake by the nutrient density method.

${ }^{*} \mathrm{P}<0.1 .{ }^{* *} \mathrm{P}<0.05 .{ }^{* * *} P<0.01$

and pulse was also of borderline significance (Spearman's $\mathrm{r}=-0.137, \mathrm{P}=0.058$ ).

Table 3 shows the estimated means of SBP, DBP and pulse according to the tertile category of dietary seaweed intake after adjustments for age and BMI. Boys with low, middle and high intake of seaweed had DBP readings of $62.8,59.3$ and $59.6 \mathrm{mmHg}$, respectively $(P=$ 0.11 , trend $P=0.038)$. Neither SBP nor pulse was associated with seaweed intake. Girls with higher seaweed intake had significantly lower SBP than those with lower seaweed intake $(P=0.037$, trend $P=0.030)$. The DBP of girls with low seaweed intake was higher than those of middle and high intake of seaweed.

Among seaweeds, nori (dried purple laver) was taken most common among our subjects (geometrical mean:

Table 1 Characteristics of 417 studied preschool children

\begin{tabular}{|c|c|c|c|c|}
\hline \multirow[b]{2}{*}{ n } & \multicolumn{2}{|c|}{ Boys } & \multicolumn{2}{|c|}{ Girls } \\
\hline & \multicolumn{2}{|c|}{223} & \multicolumn{2}{|c|}{194} \\
\hline Age (years) ${ }^{a}$ & 5.14 & $(0.89)$ & 5.12 & $(0.89)$ \\
\hline Height $(\mathrm{cm})^{\mathrm{a}}$ & 106.9 & $(7.1)$ & 106.6 & $(7.3)$ \\
\hline Weight $(\mathrm{kg})^{\mathrm{a}}$ & 17.5 & (2.6) & 17.3 & (2.6) \\
\hline BMI $\left(\mathrm{kg} / \mathrm{m}^{2}\right)^{\mathrm{a}}$ & 15.2 & $(1.3)$ & 15.2 & $(1.5)$ \\
\hline $\mathrm{SBP}(\mathrm{mmHg})^{\mathrm{a}}$ & 98.7 & (13.0) & 99.5 & (12.4) \\
\hline $\mathrm{DBP}(\mathrm{mmHg})^{\mathrm{a}}$ & 60.6 & $(11.1)$ & 62.2 & $(11.8)$ \\
\hline Pulse (beat $/ \mathrm{min})^{\mathrm{a}}$ & 93.6 & $(15.4)$ & 96.5 & (13.6) \\
\hline \multicolumn{5}{|l|}{ Diet } \\
\hline Total energy intake $(\mathrm{kcal} / \mathrm{day})^{\mathrm{b}}$ & 1446 & $(1411,1483)$ & 1337 & $(1304,1372)$ \\
\hline Salt intake $(g / \text { day })^{b}$ & 5.98 & $(5.77,6.19)$ & 5.74 & $(5.53,5.96)$ \\
\hline Salt intake $(\mathrm{g} / 1000 \mathrm{kcal})^{\mathrm{b}}$ & 4.13 & $(4.02,4.23)$ & 4.28 & $(4.17,4.40)$ \\
\hline Seaweed intake $(g / \text { day })^{b}$ & 0.67 & $(0.58,0.78)$ & 0.76 & $(0.64,0.89)$ \\
\hline Seaweed intake $(\mathrm{g} / 1000 \mathrm{kcal})^{\mathrm{b}}$ & 0.49 & $(0.42,0.56)$ & 0.58 & $(0.49,0.68)$ \\
\hline
\end{tabular}

${ }^{a}$ mean (SD); ${ }^{b}$ geometrical mean and $95 \%$ confidence interval

SBP, systolic blood pressure; DBP, diastolic blood pressure; SD, standard deviation 
Table 3 Adjusted means of blood pressure and pulse according to the tertiles of dietary seaweed intake ${ }^{a}$

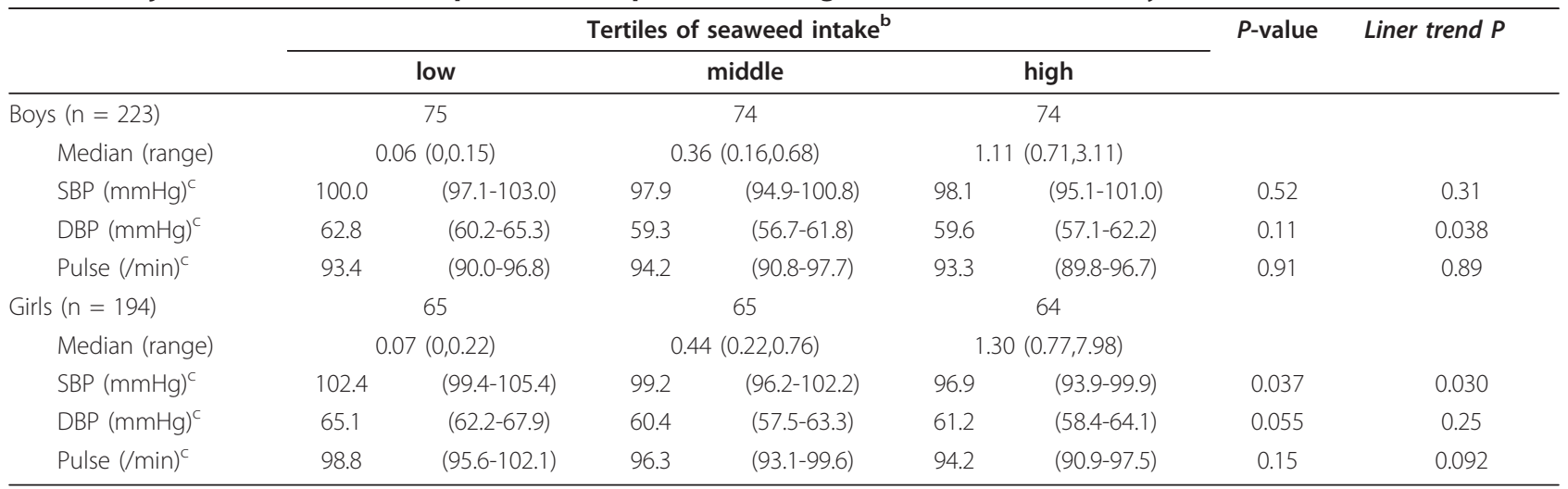

SBP, systolic blood pressure; DBP, diastolic blood pressure

${ }^{a}$ Adjustments for age and BMI.

${ }^{b}$ Seaweed intake was controlled for total energy intake by the nutrient density method.

'Estimated mean and 95\% confidence interval

$0.37 \mathrm{~g} /$ day). The association of nori intake with blood pressure was similar to that of total seaweed intake. For example, boys with low, middle and high intake of nori had DBP readings of $61.4,61.7$ and $58.6 \mathrm{mmHg}$, respectively (trend $P=0.057$ ). Girls with low, middle and high intake of nori had SBP readings of 100.6, 101.1 and 97.0 mmHg, respectively (trend $P=0.040$ ).

In order to see whether using parent-reported height and weight could influence the results, we assessed the association between seaweed intake and blood pressure among 53 boys and 50 girls whose measurements of height and weight were obtained. When the measured BMI was used as a confounder, boys with low, middle and high intake of seaweed had DBP readings of 64.7, 57.7 and $54.8 \mathrm{mmHg}$, respectively (trend $P=0.075$ ). Girls with low, middle and high intake of seaweed had SBP readings of $99.6,98.9$ and $92.5 \mathrm{mmHg}$, respectively (trend $P=0.032$ ).

We repeated the same analyses including other dietary factors as a confounder. Salt or sodium intake did not affect the negative association between seaweed intake and DBP among boys. The negative association between seaweed intake and SBP was also unaltered among girls. Additional adjustment for other mineral intakes (potassium, calcium, magnesium) also did not change the associations observed. When vegetable, fruit or fat intake was added as a confounder, the results were not substantially altered.

In addition, we assessed the association between seaweed intake and blood pressure after additional adjustment for non-dietary lifestyle factors. Sleeping habits (sleeping time in hours or the time when they got up or went to bed) or sedentary lifestyle time (total minutes of watching television or video-gaming, and reading a book) did not affect the association observed. We got data about physical activity only among 110 boys (Mean
(SD): 98.0 (13.3) $\mathrm{mmHg}$ for SBP and 60.4 (12.1) $\mathrm{mmHg}$ for DBP) and 85 girls (Mean (SD): 98.5 (13.6) $\mathrm{mmHg}$ for SBP and 60.7 (SD: 10.2) $\mathrm{mmHg}$ for DBP). Although the observed association became non- significant after additional adjustment for physical activity, the tendency in the negative association between seaweed intake and blood pressure was not altered. After additional adjustments for passive smoking or years of mother's education, the negative association between seaweed intake and blood pressure were observed.

Finally, we re-examined the association between seaweed intake and blood pressure after excluding 4 children who took medications for common cold on the day of blood pressure measurement. Along with the results among all subjects, seaweed intake was negatively related to DBP in boys (trend $P=0.024$ ) and to SBP in girls (trend $P=0.028$ ).

\section{Discussion}

Although there is much evidence for dietary risk factors for hypertension in adults, few studies of children have been reported [14-21]. Even the association between salt intake and blood pressure has been inconsistent among children $[14,15]$. Several studies have demonstrated the negative associations of blood pressure with calcium and magnesium among children [16-19], but very few researchers have examined whether the other dietary factors might affect blood pressure in childhood [19-21]. To our knowledge, this study is the first to demonstrate an association between seaweed intake and blood pressure in healthy children. Seaweed intake was negatively related to DBP in boys and to SBP in girls. Although we cannot prove a causal relationship because of a crosssectional design of this study, the finding suggests that seaweed might have beneficial effects on blood pressure among children. 
Our study of 3- to 6-year-old Japanese children showed that the difference between the highest and lowest tertiles was $3.5 \mathrm{mmHg}$ in DBP among boys and 5.5 $\mathrm{mmHg}$ in SBP among girls. Decreasing blood pressure in healthy children would be potentially beneficial for blood pressure control in the future. Among Japanese adults aged 40 to 49 years, the multivariate-adjusted hazard ratio of all-cause mortality for each $10-\mathrm{mmHg}$ SBP increase was reported to be 1.37 times in men and 1.19 in women during 9.8 years of follow-up [34]. That for each $10-\mathrm{mm} \mathrm{Hg}$ DBP was 1.46 times in men and 1.40 times in women.

The negative association between seaweed and blood pressure in our study is supported by the results of several experimental studies [23-27]. A diet containing powdered brown seaweed lowered blood pressure and reduced the incidence of stroke in salt-loaded, strokeprone spontaneously hypertensive rats [SHRs] [23]. Hydrolysates of wakame (Undaria pinnatifida), a kind of seaweed, were reported to decrease systolic blood pressure after oral administration in SHRs [24]. Peptides isolated from wakame also had inhibitory activity for angiotensin 1-conversing enzyme, causing an antihypertensive effect [25-27]. In addition, Ikeda et al. found that the administration of wakame delayed the development of stroke signs and improved the survival rate of saltloaded, stroke-prone SHRs, although there was no significant difference in blood pressure changes compared with the control group [35]. These findings suggest that seaweed may have preventive effects on hypertension and cerebrovascular diseases.

However, only a few epidemiological studies have reported an association between seaweed intake and blood pressure, and the results have been inconsistent [28-31]. Among 62 middle-aged patients with mild hypertension in Sweden, Krotkiewski et al. observed a significant decrease in mean blood pressure after the patients were given 12 and $24 \mathrm{~g}$ /day seaweed fiber for 4 weeks [28]. In hypertensive elderly Japanese patients, systolic and diastolic blood pressure decreased after the patients received daily doses of $5 \mathrm{~g}$ of dried seaweed powder for 8 weeks [29]. In a cross-sectional study of 190 hypertensive elderly Japanese patients, the patients treated with a low dose of a single drug ate more fruits and seaweed than the patients treated with a high dose of a single drug or multiple drugs, which suggested that the habitual intake of these food might help the control of blood pressure [30]. However, among 7,081 Korean men 30 years of age and older, participants with metabolic syndrome, including hypertension, showed a higher intake of seaweed and oily foods than did participants without metabolic syndrome [31]. These studies were conducted among adults, and, in this study, the relationship of seaweed intake to blood pressure has been first demonstrated among children.

In our study, seaweed seemed to have greater relationships with DBP than SBP among boys. Meanwhile, it seemed to have greater relationships with SBP than DBP among girls. Although the effects of seaweed intake on blood pressure might be different in mechanism between boys and girls, the reason for the discrepancy is unclear. In the studies among adults, one study [31] included only men and the others [28-30] analyzed the association in mixed group of men and women. More reports are needed to determine the association by sex.

The underlying mechanism responsible for the association between seaweed and blood pressure remains to be clarified. Seaweed contains large quantities of minerals and alginate, which is a kind of dietary fiber. Alginate has been reported to reduce blood pressure [36], and Yamori et al. presumed that alginic acid in seaweed may cause the inhibition of intentional sodium absorption [23]. Potassium, calcium and magnesium also have been reported to reduce blood pressure in observational studies $[13,16,17]$ and intervention trials $[9-11,18]$. However, the results among our subjects did not show associations between dietary potassium, calcium and magnesium intake and blood pressure. Nonetheless, we cannot deny the possibility that simultaneous intake of several minerals through seaweed may be effective for blood pressure. Alternatively, other ingredients may play a role in the control of blood pressure since alginate or each mineral in seaweed is lower than the effective dose needed to lower blood pressure. The whole diet pattern including seaweed intake is also possible to be responsible for the lower blood pressure.

Although a dietary record would be more accurate or better if it had been used for a longer time or repeated over different seasons, using a dietary record was one of merits in this study. One limitation is that blood pressure was measured only once, which may have caused a large measurement error. However, it is unlikely that such a measurement error was directly dependent on seaweed intake. Nonetheless, repeated measurements are best practice and necessary in future studies. Another limitation was that height and weight were reported by the parents. However, the correlation coefficient between parents' reports and measured ones ranged from 0.90 to 0.96 for height and 0.95 to 0.99 for weight among 170 first-grade and 206 fourth-grade Japanese children [37]. In our supplementary analysis among 103 children, the intra-class correlation between parent-reported and measured height and weight was high. Furthermore, the negative associations between seaweed intake and blood pressure were observed among them after the measured BMI was used as a 
confounder. Therefore, these differences would not greatly change the associations observed in our study. We also must note that BMI might not be necessarily a very good maker of fatness in growing children. Finally, the generalizability of our study is limited by the fact that our subjects were ethnically homogeneous Japanese children, whose diets differ from those of Western children.

\section{Conclusions}

We have demonstrated a negative association between dietary seaweed intake and blood pressure among healthy children. Seaweed is a popular traditional foodstuff that is widely eaten among both children and adults in Japan. Not only do our results suggest that seaweed intake may have beneficial effects on blood pressure in children, but they also provide the possibility of creating a new, earlier-in-life strategy for the prevention of hypertension in adults.

\section{Abbreviations}

BMI: Body mass index; DBP: diastolic blood pressure; SBP: systolic blood pressure.

\section{Acknowledgements}

This work was supported by grants from the Ministry of Education, Culture, Sports, Science and Technology, and the Ministry of Health, Labor and Welfare, and by Gifu University Research Grant Program. None of the authors have financial interests related to this paper.

\section{Author details}

${ }^{1}$ Department of Epidemiology and Preventive Medicine, Gifu University Graduate School of Medicine, 1-1 Yanagido, Gifu 501-1194, Japan. 2Department of Food and Culture science, Aichi Bunkyo Women's College, 2-9-17 Inaba, Inazawa, Aichi 492-8521, Japan.

\section{Authors' contributions}

Author KW wrote the paper. Author CN designed the study and directed its implementation, including quality assurance and control. Author KN helped designing the study's analytic strategy. Author YT, MT, and YS conduct the literature review and prepare the Discussion sections of the text. Author KW, SO, KY and KA helped supervise the field activities. All authors read and approved the final manuscript.

\section{Competing interests}

The authors declare that they have no competing interests.

Received: 23 May 2011 Accepted: 10 August 2011

Published: 10 August 2011

\section{References}

1. Ueshima H, Sekikawa A, Miura K, Turin TC, Takashima N, Kita Y, Watanabe M, Kadota A, Okuda N, Kadowaki T, et al: Cardiovascular disease and risk factors in Asia: a selected review. Circulation 2008, 118:2702-2709.

2. Chen $X$, Wang Y: Tracking of blood pressure from childhood to adulthood: a systematic review and meta-regression analysis. Circulation 2008, 117:3171-3180.

3. Berenson GS, Srinivasan SR, Bao W, Newman WP, Tracy RE, Wattigney WA: Association between multiple cardiovascular risk factors and atherosclerosis in children and young adults. The Bogalusa Heart Study. N Engl J Med 1998, 338:1650-1656.

4. Beauloye V, Zech F, Tran HT, Clapuyt P, Maes M, Brichard SM: Determinants of early atherosclerosis in obese children and adolescents. J Clin Endocrinol Metab 2007, 92:3025-3032.
5. Sacks FM, Svetkey LP, Vollmer WM, Appel LJ, Bray GA, Harsha D Obarzanek E, Conlin PR, Miller ER, Simons-Morton DG, et al: Effects on blood pressure of reduced dietary sodium and the Dietary Approaches to Stop Hypertension (DASH) diet. DASH-Sodium Collaborative Research Group. N Engl J Med 2001, 344:3-10.

6. Chobanian AV, Bakris GL, Black HR, Cushman WC, Green LA, Izzo JL Jr, Jones DW, Materson BJ, Oparil S, Wright JT Jr, Roccella EJ: Seventh report of the Joint National Committee on Prevention, Detection, Evaluation, and Treatment of High Blood Pressure. Hypertension 2003, 42:1206-1252.

7. Vollmer WM, Sacks FM, Ard J, Appel LJ, Bray GA, Simons-Morton DG, Conlin PR, Svetkey LP, Erlinger TP, Moore TJ, Karanja N: Effects of diet and sodium intake on blood pressure: subgroup analysis of the DASHsodium trial. Ann Intern Med 2001, 135:1019-1028.

8. Chobanian AV, Hill M: National Heart, Lung, and Blood Institute Workshop on Sodium and Blood Pressure: a critical review of current scientific evidence. Hypertension 2000, 35:858-863.

9. McCarron DA, Morris CD: Blood pressure response to oral calcium in persons with mild to moderate hypertension. A randomized, doubleblind, placebo-controlled, crossover trial. Ann Intern Med 1985, 103:825-831.

10. Witteman JC, Grobbee DE, Derkx FH, Bouillon R, de Bruijn AM, Hofman A: Reduction of blood pressure with oral magnesium supplementation in women with mild to moderate hypertension. Am J Clin Nutr 1994, 60:129-135.

11. Hatzistavri LS, Sarafidis PA, Georgianos PI, Tziolas IM, Aroditis CP Zebekakis PE, Pikilidou MI, Lasaridis AN: Oral Magnesium Supplementation Reduces Ambulatory Blood Pressure in Patients With Mild Hypertension. Am J Hypertens 2009, 22:1070-1075.

12. Zhou B, Zhang X, Zhu A, Zhao L, Zhu S, Ruan L, Zhu L, Liang S: The relationship of dietary animal protein and electrolytes to blood pressure: a study on three Chinese populations. Int J Epidemiol 1994, 23:716-722.

13. Van Leer EM, Seidell JC, Kromhout D: Dietary calcium, potassium, magnesium and blood pressure in the Netherlands. Int J Epidemiol 1995, 24:1117-1123.

14. Simons-Morton DG, Obarzanek E: Diet and blood pressure in children and adolescents. Pediatr Nephrol 1997, 11:244-249.

15. He FJ, Marrero NM, Macgregor GA: Salt and blood pressure in children and adolescents. J Hum Hypertens 2008, 22:4-11.

16. Gillman MW, Oliveria SA, Moore LL, Ellison RC: Inverse association of dietary calcium with systolic blood pressure in young children. Jama 1992, 267:2340-2343

17. Papandreou D, Stamou M, Malindretos P, Rousso I, Mavromichalis I: Prevalence of hypertension and association of dietary mineral intake with blood pressure in healthy schoolchildren from northern Greece aged 7-15 years. Ann Nutr Metab 2007, 51:471-476.

18. Gillman MW, Hood MY, Moore LL, Nguyen US, Singer MR, Andon MB: Effect of calcium supplementation on blood pressure in children. J Pediatr 1995, 127:186-192

19. Simon JA, Obarzanek E, Daniels SR, Frederick MM: Dietary cation intake and blood pressure in black girls and white girls. Am J Epidemio/ 1994, 139:130-140.

20. Ulbak J, Lauritzen L, Hansen HS, Michaelsen KF: Diet and blood pressure in 2.5-y-old Danish children. Am J Clin Nutr 2004, 79:1095-1102.

21. Ayer JG, Harmer JA, Xuan W, Toelle B, Webb K, Almqvist C, Marks GB, Celermajer DS: Dietary supplementation with $n-3$ polyunsaturated fatty acids in early childhood: effects on blood pressure and arterial structure and function at age 8 y. Am J Clin Nutr 2009, 90:438-446.

22. Science and Technology Agency, Ed: Standard Tables of Food Composition in Japan (5th revised and enlarged edition) (in Japanese). Tokyo Bureau of the Ministry of Finance; 2008.

23. Yamori $Y$, Nara $Y$, Tsubouchi $T$, Sogawa $Y$, Ikeda $K$, Horie R: Dietary prevention of stroke and its mechanisms in stroke-prone spontaneously hypertensive rats-preventive effect of dietary fibre and palmitoleic acid. J Hypertens Supp/ 1986, 4:S449-452.

24. Sato M, Oba T, Yamaguchi T, Nakano T, Kahara T, Funayama K, Kobayashi A Nakano T: Antihypertensive effects of hydrolysates of wakame (Undaria pinnatifida) and their angiotensin-I-converting enzyme inhibitory activity. Ann Nutr Metab 2002, 46:259-267.

25. Sato M, Hosokawa T, Yamaguchi T, Nakano T, Muramoto K, Kahara T, Funayama K, Kobayashi A, Nakano T: Angiotensin I-converting enzyme inhibitory peptides derived from wakame (Undaria pinnatifida) and their 
antihypertensive effect in spontaneously hypertensive rats. J Agric Food Chem 2002, 50:6245-6252.

26. Suetsuna $\mathrm{K}$, Nakano $\mathrm{T}$ : Identification of an antihypertensive peptide from peptic digest of wakame (Undaria pinnatifida). J Nutr Biochem 2000, 11:450-454.

27. Suetsuna K, Maekawa K, Chen JR: Antihypertensive effects of Undaria pinnatifida (wakame) peptide on blood pressure in spontaneously hypertensive rats. J Nutr Biochem 2004, 15:267-272.

28. Krotkiewski M, Aurell M, Holm G, Grimby G, Szczepanik J: Effects of a sodium-potassium ion-exchanging seaweed preparation in mild hypertension. Am J Hypertens 1991, 4:483-488.

29. Hata Y, N K: Clinical effects of brown seaweed, Undaria pinnatifida (wakame), on blood pressure in hypertensive subjects. Journal of clinical biochemistry and nutrition 2001, 30:43-53.

30. Ono A, Shibaoka M, Yano J, Asai Y, Fujita T: Eating habits and intensity of medication in elderly hypertensive outpatients. Hypertens Res 2000, 23:195-200.

31. Shin A, Lim SY, Sung J, Shin HR, Kim J: Dietary intake, eating habits, and metabolic syndrome in Korean men. J Am Diet Assoc 2009, 109:633-640.

32. Wada K, Nakamura K, Masue T, Sahashi Y, Ando K, Nagata C: Soy intake and urinary sex hormone levels in preschool Japanese children. Am J Epidemiol 2011, 173:998-1003.

33. Burdette HL, Whitaker RC, Daniels SR: Parental report of outdoor playtime as a measure of physical activity in preschool-aged children. Arch Pediatr Adolesc Med 2004, 158:353-357.

34. Murakami Y, Hozawa A, Okamura T, Ueshima H: Relation of blood pressure and all-cause mortality in 180,000 Japanese participants: pooled analysis of 13 cohort studies. Hypertension 2008, 51:1483-1491.

35. Ikeda K, Kitamura A, Machida H, Watanabe M, Negishi H, Hiraoka J, Nakano T: Effect of Undaria pinnatifida (Wakame) on the development of cerebrovascular diseases in stroke-prone spontaneously hypertensive rats. Clin Exp Pharmacol Physiol 2003, 30:44-48.

36. Chaki T, Kajimoto N, Ogawa H, Baba T, Hiura N: Metabolism and calcium antagonism of sodium alginate oligosaccharides. Biosci Biotechnol Biochem 2007, 71:1819-1825.

37. Sekine M, Yamagami T, Hamanishi S, Kagamimori S: Accuracy of the estimated prevalence of childhood obesity from height and weight values reported by parents: results of the Toyama Birth Cohort study. $J$ Epidemiol 2002, 12:9-13.

doi:10.1186/1475-2891-10-83

Cite this article as: Wada et al: Seaweed intake and blood pressure levels in healthy pre-school Japanese children. Nutrition Journal 2011 10:83.

\section{Submit your next manuscript to BioMed Central and take full advantage of:}

- Convenient online submission

- Thorough peer review

- No space constraints or color figure charges

- Immediate publication on acceptance

- Inclusion in PubMed, CAS, Scopus and Google Scholar

- Research which is freely available for redistribution 